\title{
Implementing a service learning class for undergraduate engineers with little required budget
}

\section{Dr. Joan B Schuman, Missouri University of Science \& Technology}

Dr. Joan Schuman is an assistant teaching professor in the Engineering Management at Missouri S\&T. She has a B.S. in Mechanical Engineering from University of Arkansas and completed her Ph.D. in Polymer Science and Engineering. Schuman teaches a variety of courses including several in Project Management. She has several years of industrial experience in the aerospace industry but is now focusing on engineering education with a special interest in service learning.

\section{Kellie Grasman, Missouri University of Science \& Technology}

Kellie Grasman serves as an instructor in Engineering Management and Systems Engineering at Missouri University of Science and Technology. She holds graduate degrees in engineering and business administration from the University of Michigan, and began teaching in 2001 after spending several years in industry positions. She was named the 2011-2012 Robert B. Koplar Professor of Engineering Management for her achievements in online learning. She serves as an eMentor for the University of Missouri System and earned a Faculty Achievement Award for teaching. 


\section{Implementing a Service Learning Class for Undergraduate Engineers with Little Required Budget}

Abstract: Service Learning (SL) classes provide engineering students both a chance gain handson experience and to increase societal responsibility. Research has shown benefits to engineering students who engage in service learning as a part of their curriculum ${ }^{1,2}$. However, developing a SL class often requires a great deal of time in planning as well as a considerable budget for implementing projects.

In this paper, we demonstrate the development of a SL class that requires very little to no budget. This course could be used as a starting point for creating a SL program. Our class, Introduction to Project Management, introduces skills necessary in all engineering fields. Students work with area communities on projects identified by each community. Previous projects include creating walking trails, building area parks, building a senior citizen center, building a storm shelter, extending roads. Interested communities are determined through the regional planning commission. Typically, the communities are small with few resources available for improvement. The largest community with which we have worked is about 17,000 in population, but most are much smaller. Students are responsible for managing the initial phases of the projects through the development of plans, schedules and budgets. Students have two deliverables for the project during the semester. The midterm deliverable is a white paper with preliminary project data. At the end of the semester, student teams deliver work plans for their projects. These work plans include preliminary budget, schedule and design information. The deliverables can then be used by the communities as a tool for grant applications. The regional planning commission aids the communities by finding applicable funding agencies. Team web pages are used by students and instructor to communicate project information and status during the project. Methodology and possible follow up courses are discussed in the paper. Reflective work completed by students toward the end of the term suggests the students feel strongly that they are helping the communities and that their experiences could change the type of volunteer work some students pursue in the future.

\section{Introduction}

To be fully prepared for a professional career in the engineering field requires students to develop different types of skills. According to ABET, engineering baccalaureate graduates should possess a set of five "hard" skills and a set of six professional skills ${ }^{3,4,5}$. The professional skills, outlined below, are skills that employers desire from engineering professionals.

(1) an ability to function on multidisciplinary teams

(2) an understanding of professional and ethical responsibility

(3) an ability to communicate effectively

(4) the broad education necessary to understand the impact of engineering solutions in a global, economic, environmental, and societal context

(5) a recognition of the need for, and an ability to engage in life-long learning

(6) a knowledge of contemporary issues

Service learning projects have become popular within engineering programs in part due to the 
fact that service learning can be an effective means of developing the professional skills outlined by $\mathrm{ABET}^{6}$. Project-based learning in general can provide a venue for team building and communication skills. Service learning projects can also provide an understanding of professional and ethical responsibility, the impact of engineering solutions in a global and societal context, as well as knowledge of contemporary issues.

Global service learning projects have become popular with students as well ${ }^{7}$. These types of projects allow students to experience different cultures and make an impact on the global community. The downside to developing courses using global service learning projects is the cost of such projects and the time involved in the course preparation and travel ${ }^{8}$. This type of coursework is not available to all students due to the time required.

Not all service learning courses must require a large budget or travel commitments. This paper outlines the process to develop a service learning course which is applicable to all engineering disciplines and initially requires almost no budget.

\section{Course Framework}

All engineering students can benefit from learning basic project management skills and many students are motivated by the idea of helping others with their skills. All engineering students and graduates will work at some point on projects and a better knowledge of the tools and skills necessary for successful projects will only enhance their engineering skills. Our class was designed to provide the students real life project experience as well as allow the students to help the communities.

Missouri S\&T is a small technological school with just over 7000 students in a rural area in the Midwest with 75 percent of the students majoring in engineering. Class demographics are typically about 30 percent female and about 20 percent minority. Since the area is rural, surrounding communities have few resources for improvement to their communities. The class, Introduction to Project Management, has been developed as a service learning course which works with area communities. Students learn basic best practices for project management as well as basic tools for tracking and controlling projects. The course is a junior level course required in the Engineering Management curriculum and students are generally junior or senior level engineering students. A majority of the students are Engineering Management majors, but the course is growing in popularity with many students from other majors who are minoring in Engineering Management or just taking the class because of the perceived importance in their career. Students have customers (communities) to whom they report their project plans.

The class also serves as a means to help area communities with the planning and design of improvement projects and has been successful due to a partnership with the planning commission in this region. The Meramec Regional Planning Commission (MRPC) first identifies communities that are interested in working with the class prior to the beginning of the semester. The communities are typically within a 50 mile radius to reduce the travel time for the students. MRPC then schedules the initial meeting with the communities. After the semester is completed, the MRPC takes the project plans and identifies funding possibilities and provides aid to the communities in the grant applications. These communities are typically small, some with 
populations as small as 1500 and the largest community being the home to our university with population of about 17,000 .

After MRPC has identified the community with which the class will work, the community leaders are then tasked with compiling a list of projects in which the community would be interested in developing. The community leaders may list projects for which a budget has been acquired as well as possible projects in which no current funding exists. Since the class typically consists of about 30-35 students, the goal is to have 10-12 projects from the communities. During the initial meeting with the communities, the projects are discussed and developed using brainstorming techniques. For undergraduate engineering students, construction type projects work well. Less concrete projects such as beautification projects are more difficult for undergraduates. It is imperative that community leaders understand the scope of the work provided by the students and the limitations. Students are unable to provide final engineering drawings and in this class are only able to provide planning for the projects.

Prior to the beginning of the semester, community leaders review the project description developed by the initial team and assign a community member who has an interest in and knowledge of the project to be the project champion. It is suggested to the community that assigning different champions to each project not only reduces the time involved by the project champions, but also involves more community members and hopefully spurs more interest within the community about the projects. A program manager from the community is also selected who preferably is not a project champion, and will become the person who oversees the projects within the community. Having a program manager who is not a project champion allows for that person to step in to the project champion role if someone is unable to continue in that capacity. Typically, the mayor of the city or the city planner makes a good program manager. Contact information for each champion and the program manager is compiled into a working document which is provided to all project teams and other stakeholders.

During the first two weeks of class, the community leaders attend the class and present the projects to the students. Students should have had access to the working document with project descriptions and are encouraged to ask questions of and interact with community members. The need for the projects becomes more real to the students when the customers make the presentations. For project selection, students are allowed to list the top three projects in which they are interested. Projects are assigned by instructor based on a first come first serve basis with some consideration of the skill set of the students from their work experience or major. The projects are varied in type and appeal to students with different backgrounds. For example, one semester an electrical engineering student was interested in taking the class and was concerned about finding a project in which she would be interested. That semester, one project was dealing with the power lines in the city center. Typically each semester, civil engineering students take the class and civil engineering projects are almost always among the identified projects. Some students will show interest in a project due to their work experience. One student who had worked in the summers as a volunteer firefighter wanted to work on the design of a new fire station. In the past, most students have been assigned to one of their top three selections.

Once the student teams are assigned to the projects, the working document with the project descriptions is updated with student contact information and provided to all necessary 
stakeholders. Next, students are required to travel to the community at least once to meet with their project champions. A course requirement provides a time limit of two weeks after project assignment for the initial trip by the student team to the community. Students gather data regarding the scope of the projects from which they develop the preliminary project objectives. The face-to-face meeting with the project champion is important to allow better understanding of the desired objectives and foster greater communication within the project team. Additional trips are made if deemed necessary by project teams. The Engineering Management Department will reimburse student travel to and from the communities. The required budget for travel reimbursement depends on the distance to the community. Typically for travel of 10-20 miles distance students will not seek reimbursement. For spring of 2012, the distance was 45 miles and the budget for reimbursement was approximately $\$ 600$.

Throughout the semester, students develop a scope, budget and schedule for their project. These aspects of their documents will be built as the course material is covered in class. Students are required to provide status on their progress as part of homework assignments. These status reports are uploaded to the team web site. Also, two project meetings for each team with the instructor are a requirement during the semester to address issues and ensure progress on the projects. The instructor analyzes status reports as well as project issues outlined during the project management meetings in order to provide feedback to students as the semester progresses.

At the end of the semester, the class travels to the community for a final meeting. Typically the community provides food (either by a pot luck dinner or catering) for this meeting. All interested community members are invited and a town hall style meeting is held in which the students present their projects to the community members. Often, several members of the community who have not been involved with the class attend this meeting. According to the reflective work (see below), students find the presentation of their work to the customer to be a motivating factor throughout the semester.

\section{Deliverables}

By semester midterm, students are required to deliver a white paper to the project champions. This is a two page paper with a preliminary plan including a budget and schedule for the project. Students must state project objectives and provide preliminary data for approval by the project champions. Students also present this data to the class (no community members) for critique by instructor and their peers.

At the end of the semester, the students are required to deliver and present their final work plans to the community. Work plans consist of a finalized project plan containing a more detailed and accurate budget and schedule. Students are assessed on the accuracy and detail in the work plan as well as how well the plan will achieve the project objectives. An electronic version of all work plans are compiled and delivered to the program manager in the community as well as to MRPC, who then uses these plans to identify and apply for grant funding for applicable projects. Again, it is important to emphasize that for this particular class, the students only plan and schedule the projects but do not execute the project plans. 


\section{Liability}

For liability purposes, all documents provided to the community leaders, project champions or planning commission are labeled with the following disclaimer: All plans and/or documents contained herein were prepared by students and not by licensed professionals. Also, a draft watermark is placed on all documents. Care is taken to ensure that community members understand that engineering and construction work must be completed by licensed professionals.

\section{Example Projects}

As mentioned previously, the types of project vary considerably for each community. However, to date, all communities have identified a community hiking/walking trail as one project. The type and use of the trail has varied to some degree, but need to provide communities with a safe environment to exercise and recreate is there. Other types of recreational facilities include disc golf courses, parks with playground equipment, athletic fields, and an ice skating rink.

Construction type projects seem to be of great interest to the students. Some of the construction projects include roads development, development of a comprehensive sidewalk system, low water bridge development, storm shelters, animal shelters, and police station renovation to name a few.

Other types of projects include city beautification plans, memorial programs and sewer or drainage issues. Several projects have dealt with traffic flow issues around schools or in downtown areas.

\section{Course Tools}

Microsoft Project (MSP) is used as a project management scheduling and tracking tool. MSP is a powerful project management software package and is currently used with many projects in industry. MSP 2010 is currently loaded on our campus computers in several locations including a computer lab in the Engineering Management building. The class is taught several times in the computer lab to provide instruction and hands on experience for the students. Students create their project schedule and resource allocation using MSP. Students also practice project tracking and forecasting using MSP.

Introduced in the fall 2012 semester, a course web site serves as a shared workspace for project teams. The course site is created using Google Sites, a service within Google Apps for Education. Google Apps for Education is supported by the campus, allowing students to create an individual Google account associated with their university computing login. With this account, students can use their login to access email, calendar, document and file sharing tools. Additionally, Google Apps allows students to create and edit web sites and pages through the Google Sites tool.

Course site access is restricted to students enrolled in the course, the instructor, and a web manager. A list page displays each team's membership along with a link to a Team Project Site for each team. Access to each team's Project Site is limited to individual team members, the 
instructor, and web manager. As a result, students are not allowed to view or edit the sites of other teams in the class. Each team's project site includes pages for Team Home, Project Objectives, Project Status, and Project Documents. Students use the Team Home page to display images of each team member, including their role on the team, major and hometown. Additionally, teams post a Project Overview here including a brief text introduction and images/photos relevant to their project. Teams prepare concise goals for their project as displayed on the Project Objectives page. The Project Status page serves as a location for teams to post status reports at regular intervals for instructor review. The Project Documents page is structured as a digital file cabinet, allowing students to add files of various formats (pdf, Word, PowerPoint, Excel and Google Docs). Student teams use the file cabinet to collaborate on drafts of project deliverables as well as submit final versions for review and grading by the instructor. The instructor may access the team file cabinet to share rubrics, grade information and feedback with each team.

Overall, the course site was well received by students, as they found it a convenient way to collaborate with fellow teammates and the instructor. Though many students entered the course with little to no experience editing web pages, they found it comfortable to work with the structured Team Project Sites that were created in advance for each team. At the completion of the semester, each student maintains access to their team site. In future semesters, use of the course site may be expanded to include increased utilization as a collaboration tool between teams and community sponsors as well as a tool for peer to peer evaluation of project team progress.

\section{Reflection}

For the fall semester 2012, students were given reflective work as part of the course study. Students were asked to reflect on the following questions:

1. Did having a "real" customer improve your performance? Explain

2. Did you feel that you were helping the community with the project? Explain.

3. Do you see yourself doing service in any community in the future? Has this class experience changed that outlook?

Eighty-five percent of students felt that having a "real" customer improved their performance, while $11.5 \%$ stated that their experience was improved due to the fact that the projects were real world. A resounding $88.5 \%$ of the students stated that they felt that their project helped the community in which they worked while $7.7 \%$ felt that the community would be helped if the projects were funded and completed. Also, $88.5 \%$ planned on performing community service in the future and $42.3 \%$ of the students felt that the class experience had affected that outlook. Many of those students felt that the class experience had not affected their desire to participate in community service, but it had changed how they looked at community service or the type of community service that they could perform. One student stated "I have always thought that community service is important. This project was different, however in that I was able to use my knowledge and skills about engineering to help someone rather than just doing the usual "grunt" work that volunteering sometimes entails. I will definitely continue volunteering in the future, and this project has opened my eyes to how volunteering my engineering skills can be used for the greater good." Half of the students felt that the class had had no bearing in their interest in 
doing community service in the future. Of those, most were already performing community service as a part of an organization to which they belong.

The reflective work, which was not required in the class initially, appears to affect the student's view of their work in the class. Although, more study is needed for this class, the act of requiring the students to reflect upon these topics has been shown to make them more aware of the impact they have had or could have in the future 9 .

\section{Future work}

Although the projects outlined in the paper do provide a real world example for students, experience is only gained in the planning, budgeting and scheduling aspects of project management and not project execution. The class is viewed as a first step in building a servicelearning component for the students. The ideal next step would be to acquire funding to complete a select number of projects and offer a course in which projects that were planned during the fall and spring semesters would be executed. The most appropriate timeframe for such a class would be over the summer semester, which would hopefully reduce the number of weather delays since most of the projects are outside.

Only students who had completed the initial Introduction to Project Management class would be allowed to enroll in the second course. As part of the course, students would participate in the project selection from projects previously planned. Students would be responsible for overseeing the project's completion and tracking the budget and schedule during the project execution. As the project managers, students would be responsible for ensuring the proper resources were obtained as needed for the most efficient use of time. Students would also be required to report on issues and lessons learned throughout the project. In this case, students would not complete the work, but oversee project execution.

The main advantage of a follow up course for the students is a more complete picture of tasks involved in successful project management. The students would have the ability to gain more skills necessary to perform more successfully on a project team. The main advantage to the communities would obviously be the successful completion of a project. The main disadvantage of the follow up class is the required budget. As budgets for higher education are continually tightened, sustained funding could be an issue. A requirement for communities to match project funding could reduce the budget requirements for the universities and could potentially gain customer buy in, but could hamper the student management of the project. Further study for potential resources of funding would need to be investigated prior to course development.

\section{Conclusions}

A service learning course has been successfully developed teaching introductory project management skills to undergraduate engineering students. This class is currently being executed with little budget and requires minimal preparatory time. A large majority of the students felt having a real world experience enhanced the classroom experiences. Also, a large majority of the students felt that the projects helped the communities or will help them in the future. 
In any service learning class, it is important to question if the work actually benefits the groups for which it is completed. For the fall semester of 2012, the student perception is an overwhelming yes, the communities were helped. Measuring success for these projects might be more difficult. Certainly, the completed projects could and will be tracked over time. The number of grants awarded can also be tracked. Increases in community pride and volunteerism are more difficult to measure but could be an outcome of the project plans. Also, tracking the customer satisfaction is another measure of success. In most cases, the customers were very pleased with the work the students completed, but some felt the chances of project completion were slim due to lack of funds.

The addition of a follow up class in which the selected project plans are actually executed would greatly increase the interest and satisfaction of the area communities.

\footnotetext{
${ }^{1}$ Astin, A., Vogelgosang, L., Ikeda, E., \& Yee, J. (2000). How Service Learning Affects Students. UCLA. LA: Higher Education Research Institute.

${ }^{2}$ Dukhan,N., Schumack, M., (2010). Reflection-based assessment of service learning in undergraduate engineering. International Journal for Service Learning in Engineering, Vol 5, No. 2, pp 32-43.

${ }^{3}$ Shuman, L.J., Besterfield-Sacre, M., McGourty, J., (2005). The ABET "Professional Skills? - Can They Be Taught? Can They Be Assessed? Journal of Engineering Education.

${ }^{4}$ Prados, J.W., (1997). The Editor's Page: Engineering Criteria 2000-A Change Agent for Engineering Education, Journal of Engineering Education, Vol., 86, No. 4.

${ }^{5}$ ABET, Criteria for Accrediting Engineering Programs, Baltimore, Md.; Engineering Accreditation Commission, Nov. 11, 2003. See http://www.abet.org/accreditation-criteria-policies-documents/.

${ }^{6}$ Budny, D., Gradoville, R.T., (2011). International Service Learning Design Projects: Educating Tomorrow's

Engineers, Serving The Global Community, and Helping to Meet ABET Criterion. International Journal for Service Learning in Engineering, Vol. 6, No. 2, pp. 98-1187.

${ }^{7}$ Evans, N., (2000). Experiential Learning Around the World: Employability and the Global Economy, ed. Higher Education Policy Series 52. London and Philadelphia: Jessica Kingsley, 222p. ISBN 1-85302-736-7.

${ }^{8}$ Soerens, T., Gattis, C.; (2009). Gobal Community Development Village Network: An interdisciplinary International Service Learning Model. International Journal for Service Learning in Engineering, Vol 4, No. 1, pp. 34-47.

${ }_{9}^{9}$ Bleicher, R.E., Correia, M.G., (2011). Using a "Small Moments" Writing Strategy to Help Undergraduate Students Reflect on Their Service-Learning Experiences. Journal of Higher Education Outreach and Engagement, Vol 15, No. 4, p. 27.
} 